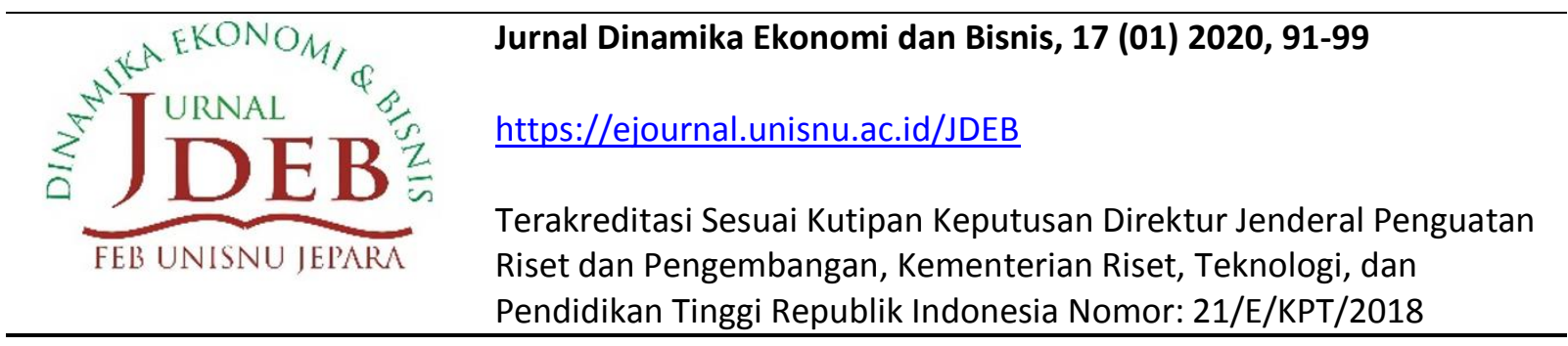

\title{
ANALISIS STRATEGI BERTAHAN PENGRAJIN ROTAN KOTA PEKANBARU
}

\author{
Nofrizal \\ Fakultas Ekonomi, Universitas Lancang Kuning \\ E-mail: Nofrizalfe@Unilak.ac.id
}

\begin{abstract}
The changing times have not changed rattan products, but they have been able to defense until now. This study aims to find out the factors that determine the defensive strategy of rattan craftsmen in Pekanbaru City. The object of the research was the rattan craftsmen in Pekanbaru City, totaling 42 business units. The data source was taken from primary and secondary data. The data collection techniques used interviews, questionnaires, and literature study. The variables in this study were categorized into two: external (opportunities and threats) and internal (strengths and weaknesses). The data analysis technique used descriptive quantitative technique. The variable measurement scale used four-point Likert Scale, from disagree to strongly agree. The results showed that the determinants of the rattan craftsmen to defense were price and reputation suitability with the average score of four, while the weak factors were the promotion form, quality of education, inflation development, CSR programs, and SME development programs with the average score of two.
\end{abstract}

Keywords: Defensive Strategy, Opportunity, Threat, Strength, Weakness

\begin{abstract}
Abstrak
Perubahan zaman tidak membuat produk rotan berubah dan mampu bertahan hingga saat ini. Penelitian bertujuan untuk mengetahui faktor-faktor yang menentukan strategi bertahan pengrajin rotan Kota Pekanbaru. Objek penelitian adalah pengrajin rotan Kota Pekanbaru berjumlah 42 unit usaha. Sumber data berasal dari data primer dan data sekunder. Teknik pengumpulan data menggunakan wawancara, kuesioner, dan studi pustaka. Variabel dibedakan menjadi dua, yaitu: eksternal (meliputi peluang dan ancaman) dan internal (meliputi kekuatan dan kelemahan). Teknik analisis data menggunakan kuantitatif deskriptif. Skala pengukuran variabel menggunakan skor 1-4, yaitu: tidak setuju-sangat setuju. Hasil penelitian menunjukkan bahwa faktor penentu pengrajin rotan dapat bertahan adalah kesesuaian harga dan reputasi dengan nilai ratarata empat, Sedangkan faktor yang masih lemah yaitu bentuk promosi, kualitas pendidikan, perkembangan inflasi, program CSR, dan program pembinaan UKM dengan nilai rata-rata dua.
\end{abstract}

Kata Kunci: Strategi Bertahan, Peluang, Ancaman, Kekuatan, Kelemahan

Sitasi: Nofrizal. (2020). Analsis Strategi Bertahan Pengrajin Rotan Kota Pekanbaru, Jurnal Dinamika Ekonomi dan Bisnis, 17 (01) 2020, 91-99.

Penulis Korepondensi:

Nofrizal

Fakultas Ekonomi,

Universitas Lancang Kuning

Nofrizalfe@Unilak.ac.id 


\section{PENDAHULUAN}

Salah satu bisnis UKM yang mampu bertahan di Pekanbaru hingga saat ini adalah pembuat kerajinan berbahan rotan di khususnya di Kota Pekanbaru yang telah berdiri sejak 1985 (Bertuahpos, 2017b). Pada saat ini pengrajin rotan yang berada Pekanbaru berjumlah 42 unit usaha (Disperinriau, 2017). Menurut (Nella Marni, 2016) di dalam perjalanan bisnis UKM Kerajinan Rotan mengalami pasang surut seperti ketika saat liburan dan hari-hari besar maka omset penjualan mengalami peningkatan hingga Rp 15-20 juta sedangkan ketika hari biasa omset penjualan Rp 400 Ribu (Bertuahpos, 2017a). UKM Pengrajin Rotan sebenarnya juga pernah mengikuti beberapa kegiatan pelatihan yang diselenggarakan oleh pemerintah Provinsi Riau dan Pemerintah Kota Pekanbaru agar produk-produk kerajinan rotan tersebut memiliki keunggulan sehingga dapat bersaing dengan produk-produk modern saat ini.

Pada saat ini di kota Pekanbaru persaingan produk-produk furniture semakin ketat dimana konsumen ditawarkan dengan produk-produk furniture yang lebih modern seperti Informa, Plaza mebel, Olympic Furniture, Toko-toko perabot dan mebel, wira kencana dan lain-lain. Selain permasalahan persaingan yang dihadapi oleh UKM Pengrajin Rotan, Faktor bahan baku sebagai bahan dasar terkadang sulit untuk di peroleh oleh pengrajin. Berdasarkan data-data dan fakta kondisi UKM Pengrajin Rotan di Pekanbaru, tentu tidak mudah untuk bertahan dengan kondisi tersebut apalagi bersaing dengan produk-produk modern saat ini. Oleh karena itu tujuan penelitian ini untuk mengetahui faktor-faktor yang mempengaruhi strategi bertahan Pengrajin Rotan Kota Pekanbaru.

\section{TELAAH PUSTAKA}

Strategi merupakan sebuah ilmu baru di dalam disiplin ilmu akademik yang datang dari masa lalu pada tahun 1960 (Porter, 1995). Akar dari Strategi mengerucut pada banyak disiplin akademik diantaranya adalah industri, ekonomi, pemasaran, keuangan, psikologi, ilmu tingkah laku, sejarah strategi dan taktik militer (Stonehouse \& Snowdon, 2007) Menurut (Thomas L Wheelen, J David Hunger, Alan N Hoffman, 2015) strategi bagaimana mencapai tujuan Way to Achieve Lingkungan Eksternal. Lingkungan eksternal. Menurut (David, 2010) eksternal faktor terdiri dari :(1) kekuatan ekonomi; (2) kekuatan sosial, budaya, demografis, dan lingkungan; (3) kekuatan politik, pemerintah dan hukum; (4) kekuatan teknologi; dan (5) kekuatan kompetitif. (Elbanna, 2010) lingkungan umum yaitu: 1) Political, 2) Economic, 3) Social, and 4) Technological (PEST) dan seluruh penyusunan pada manajemen strategik pasti memperhatikan lingkungan umum (Makro). Setelah analisis lingkungan umum dilanjutkan dengan analisis lingkungan industri menurut Porter M (Fred R. D, 2011) menyebutkan bahwa alat untuk menganalisis lingkungan pesaing terdiri dari model lima kekuatan (five forces model) yaitu Porter M dalam (Hemmatfar \& Ph, 2010) dan (Soviyanti, E., Khairani, Z., Ciptono, W. S., \& Hanafi, 2019) juga menggunakan indikator (1) Persaingan perusahaan sejenis (rivalry among competitors), (2)pendatang baru(threat of entry), (3) Ancaman barang substitusi (threat of substitutions), (4) Daya tawar pembeli (bargaining power of buyers), (5) Daya tawar penyedia input (bargaining power of supplier). 
Analisis faktor lingkungan internal merupakan kegiatan perusahaan mengidentifikasi sumber-sumber kekuatan dan kelemahan pada unit fungsional bisnis seperti fungsi pemasaran, fungsi keuangan, fungsi produksi, fungsi pelatihan dan pengembangan SDM, fungsi sistem informasi dan keterkaitan area bisnis (Keller, 2012). (Nofrizal, 2018) menggunakan faktorfaktor yang perlu diperhatikan untuk evaluasi di dalam area organisasi yaitu (1) Kultur perusahaan, (2) citra perusahaan, (3) Struktur organisasi, (4) Key staff, (5) kemudahan mendapatkan sumber daya, (6) posisi dalam pengalaman, (7) efisiensi kegiatan operasional, (8) Kapasitas kegiatan operasional, (9) Brand awareness, (10) pangsa pasar, (11) keuangan, (12) kontrak eksklusif, (13) hak paten \& Rahasia perdagangan. Di dalam penelitian ini, fokus pembahasan pada lingkungan internal yang terdiri dari pemasaran, pelatihan, dan sumber daya manusia dan keuangan yaitu mencakup sumber daya internal yang dibagi menjadi 2 (dua) yaitu Berwujud dan Tidak berwujud.

\section{METODE PENELITIAN}

Objek Penelitian ini adalah pengrajin Rotan di Jl. Yos Sudarso Rumbai Kota Pekanbaru. Sumber data yang digunakan berasal dari Primer dan Sekunder. Teknik pengumpulan data Wawancara, Kuesioner, Studi Pustaka. Identifikasi dan Operasional Variable dibedakan menjadi dua (2) yaitu Eksternal (Peluang dan Ancaman) dan internal (Kekuatan dan kelemahan). Analisis data penelitian menggunakan metode kuantitatif deskriptif dengan menggunakan skala Likert menggunakan alternative skor 1-4 terdiri tidak setuju hingga sangat setuju.

\section{HASIL DAN PEMBAHASAN}

Analisis Responden

Analisis responden usia responden di dominasi pada umur 31-40 tahun dengan persentase 26.7 persen, sedangkan sisanya didominasi pada usia 46-50 tahun. Ini berarti usia pelaku Pengrajin rotan Pekanbaru di usia yang produktif. Lama usaha pengrajin rotan di dominasi antara 8->10 tahun dengan persentase 35.7 persen, sedangkan sisanya didominasi 28 tahun. Ini berarti lama usaha berdiri sudah cukup lama. Jenis kelamin pengrajin rotan di dominasi laki-laki dengan persentase 66.7 persen, sedangkan sisanya didominasi pria. Ini berarti pria lebih banyak dari pada perempuan sehingga kinerja dapat lebih meningkat dikarenakan dalam pembuatan ini dibutuhkan tenaga yang lebih.

Tingkat pendidikan pengrajin rotan didominasi SMA dengan persentase 64.3 persen, sedangkan sisanya didominasi SMP dan Sarjana. Ini berarti pengrajin rotan masih memiliki tingkat pendidikan yang rendah. Omset per bulan pengrajin rotan didominasi 1-5 juta dengan persentase 58.3 persen, sedangkan sisanya didominasi 5-10 juta. Ini berarti pengrajin rotan masih memiliki tingkat omset yang rendah. Rata-rata pengrajin sudah mendapatkan pelatihan sebanyak 1-10 kali dengan persentase 26.7 persen, sedangkan sisanya didominasi 11-15 kali. Ini berarti pengrajin rotan masih memiliki tingkat omset yang rendah. Sumber modal pengrajin rotan di dominasi dari pribadi dengan persentase 80 persen, sedangkan sisanya 
didominasi dari pihak ketiga. Ini berarti sumber modal lebih banyak dari modal sendiri sehingga kinerja usaha juga tergantung dari modal yang dimiliki lihat gambar 1 .

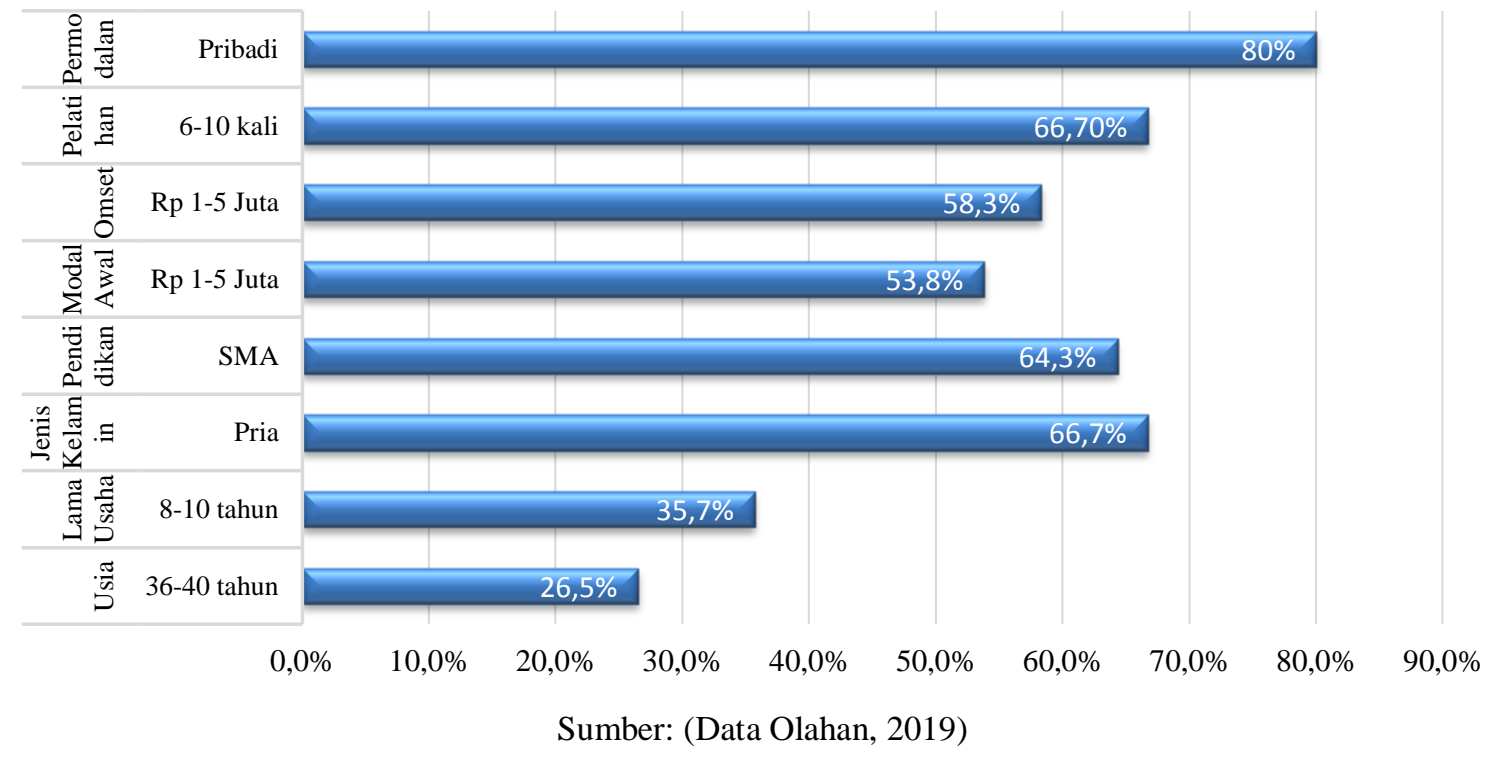

Gambar 1. Tabulasi Rekapitulasi Jawaban Responden

\section{Analisis Lingkungan Eksternal \\ Peluang}

Program pemerintah yang diluncurkan untuk pembiayaan UKMK adalah (KUR) Kredit Usaha Rakyat, diperuntukkan untuk kategori UMKM yang layak usaha, tetapi tidak memiliki agunan yang memadai untuk persyaratan perbankan. Jumlah KUR yang disalurkan dari tahun 2007 hingga tahun 2014 kepada debitur sebanyak 12.145.201 dengan total dana Rp159,2 triliun (Abidin, 2015). Adapun manfaat dari program ini adalah terjadinya peningkatan perekonomian, pengurangan kemiskinan dan membuka lapangan pekerjaan (Sudaryanto, R., \& Wijayanti, 2013). Pemerintah Republik Indonesia mengeluarkan kebijakan untuk UMKM tertuang dalam Peraturan Nomor 17 tahun 2013 tentang Usaha Mikro, Kecil, dan Menengah yang terdiri dari 64 pasal (Indonesia, 2013). Selain perhatian dari pemerintah pusat, program CSR juga digulirkan oleh industri perbankan Indonesia guna memberikan kemudahan dan akses kredit kepada para pelaku UMKM untuk di provinsi Riau saat ini sudah diatur tentang CSR yang tertuang dalam Peraturan Daerah Provinsi Riau Nomor 6 Tahun 2012 Tentang Tanggung Jawab Sosial Perusahaan Di Provinsi Riau yang bersisi tentang Program TJSP, Program Pemberdayaan Masyarakat, Program kemitraan, Program Bina Lingkungan, Pembangunan berkelanjutan dan lain-lain (JULINA, 2015).

Beralih pada ekonomi di Provinsi Riau sektor yang paling mayoritas membuka lapangan pekerjaan adalah sektor pertanian pada tahun 2017. Selain itu Sektor perdagangan juga yang mengalami peningkatan yaitu (21,91 persen) meningkat sebesar 3,26 poin dari tahun 2016 (18,65 persen). Sektor lainnya yang juga mengalami peningkatan persentase adalah sektor keuangan dan jasa perusahaan, dan sektor sosial, jasa kemasyarakatan dan perorangan. Pada sisi pertumbuhan penduduk menurut Kabupaten/Kota Tahun 2010-2020, diperkirakan jumlah penduduk provinsi Riau tahun 2015 berjumlah 6.188 .442 jiwa 


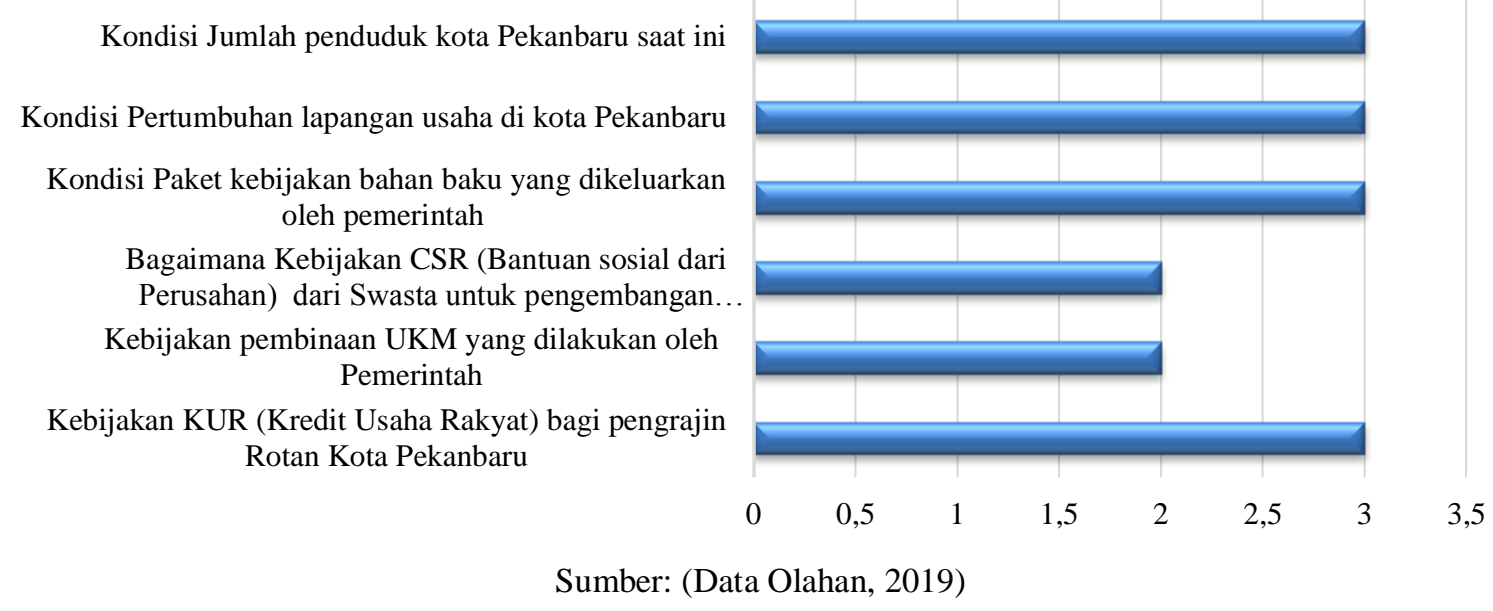

Gambar 2. Rekapitulasi Analisis Faktor Peluang

Berdasarkan gambar 2 maka faktor peluang dengan indikator kebijakan KUR, Kebijakan bahan baku, Lapangan usaha dan jumlah penduduk mendapatkan nilai rata-rata 3 (tiga). Ini berarti dapat di jadikan indikator penting pengrajin rotan, sedangkan indikator yang mendapat nilai rata-rata 2 (dua) yaitu Kebijakan CSR dan Pembinaan UKM yang memiliki nilai cukup rendah.

\section{Ancaman}

Inflasi Provinsi Riau dan Indeks Harga Konsumen (IHK berdasarkan data Pada Desember 2017 sebesar 0,49 persen dan 133,43. Inflasi Year on Year Desember 2017 terjadi karena adanya kenaikan harga pada lima kelompok pengeluaran, yaitu kelompok bahan makanan 1,66 persen, disusul kelompok minuman, makanan jadi, tembakau dan rokok 0,35 persen, kelompok perumahan, listrik, gas, air dan bahan bakar sebesar 0,05 persen. kelompok rekreasi, pendidikan dan olahraga 0,09 persen dan kelompok komunikasi, transportasi dan jasa keuangan 0,06 persen

Tinggi persaingan di industri furniture ini membuat pelaku pengrajin mebel berbahan baku rotan Pekanbaru harus waspada terdapat beberapa toko-toko yang menjual produkproduk sejenis berdasarkan hasil dari data (Info, 2018) jumlah toko yang menjual mebel/furniture di kota Pekanbaru berjumlah 83 toko. Sedangkan untuk persaingan antar pengrajin mebel berbahan rotan di Pekanbaru jumlahnya sebanyak 42-unit usaha.

Untuk mengatasi usaha rotan ini agar tetap eksis para pengusaha dan pengrajin rotan berusaha untuk mendatangkan rotan dari luar Provinsi Riau seperti dari Padang, Pulau Jawa dan Jambi. Namun permasalahannya biaya produksi rotan juga meningkat. Dan ini yang menyebabkan harga produk kerajinan rotan itu mahal. Sehingga mahalnya harga produk kerajinan rotan maka perputaran arus barang yang telah diciptakan juga lama. Sehingga tingkat penjualan sedikit. Hasil survei oleh (Nila Asmita, 2013) juga menunjukkan bahwa tingkat kesukaran dalam memperoleh bahan baku 50\% menyatakan sulit sedangkan $40 \%$ menyatakan mudah sedangkan $10 \%$ menyatakan sangat mudah. Di Kota Pekanbaru telah banyak produk-produk pengganti dari kerajinan rotan yaitu dari yang berbahan kayu, plastik, 
besi dan lain-lain. Seperti pengganti produk keranjang berbahan rotan digantikan dengan keranjang berbahan besi. Meja berbahan rotan digantikan dengan meja berbahan kayu.

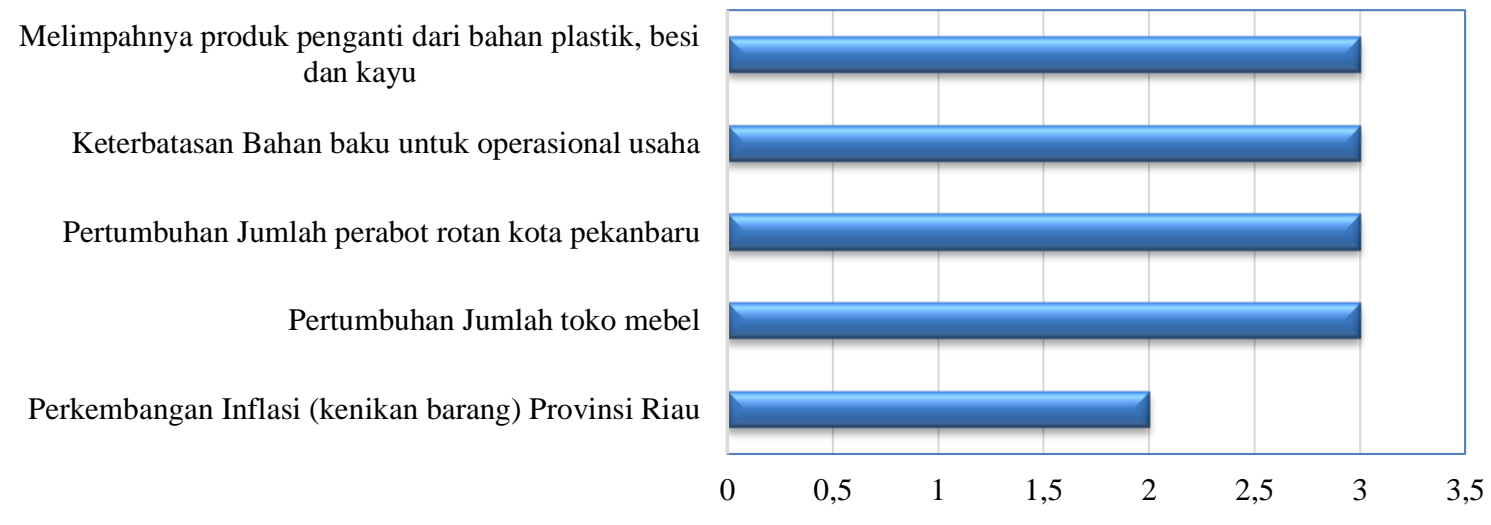

Sumber: (Data Olahan, 2019)

\section{Gambar 3. Rekapitulasi Analisis Faktor Ancaman}

Berdasarkan gambar 3 maka faktor peluang untuk indikator produk pengganti, keterbatasan bahan baku, pertumbuhan jumlah perabot, pertumbuhan jumlah mebel mendapatkan nilai rata-rata 3 (tiga), namun perkembangan inflasi memiliki dampak yang rendah yaitu rata-rata 2 (dua).

\section{Analisis Lingkungan Internal \\ Kekuatan}

Perabot rotan pertama kali didirikan oleh Bapak Syarbani pada tahun 1995 yang berlokasi di jalan Yos Sudarso no. 235 Rumbai Pekanbaru. Saat pertama kali pendirian usaha ini sudah cukup besar. Perabot rotan Bapak Syarbani ini bernama Al-Furqon. Perabot rotan Al- Furqon merupakan perabot rotan yang berdiri atas dasar kelanjutan dari perabot "Elang Perkasa”. Adapun harga jual dari produk-produk rotan ditawarkan mulai dari Rp 50.000,sampai Rp 2.000.000,- misalnya produk kursi tamu minimalis mereka jual dengan harga $\mathrm{Rp}$ 450.000,- mainan anak-anak seperti kuda-kudaan dijual dengan harga Rp 350.000,- produk tudung saji ditawarkan dengan harga $\mathrm{Rp} 150.000$,- sedangkan produk seperti piring-piring rotan dijual berkisar Rp 15.000,- hingga Rp 20.000,- (BroSis, 2018).

Mitra pengrajin rotan yaitu Pemerintah Pekanbaru dalam hal ini Dinas Perindustrian dan Perdagangan sangat mendukung kegiatan industri kecil dan menengah. Variasi produkproduk yang ditawarkan sangat beragam diantaranya kursi rotan, ayunan rotan, meja makan, meja tamu, mainan anak-anak (kuda-kudaan, enjut-enjutan, dll), vas bunga, lemari, perlengkapan dapur ,tempat buah, tempat tisu, tempat air mineral, piring, nampan, tudung saji, keranjang cucian, meja makan, laci, ayunan, bingkai, dan produk pernak-pernik rumah lainnya. Ciri khasnya itu selain warna warni, desainnya juga dibuat dengan semenarik mungkin. Tetapi ada juga beberapa produk yang kami buat warnanya itu natural aja. Usaha rotan di Pekanbaru sebagai badan usaha yang berbentuk UD (usaha dagang), maka untuk mencapai tujuannya juga membentuk suatu struktur orang berbentuk garis atau lini. 
Kemudahan menyediakan Ketersedian mesin/peralatan

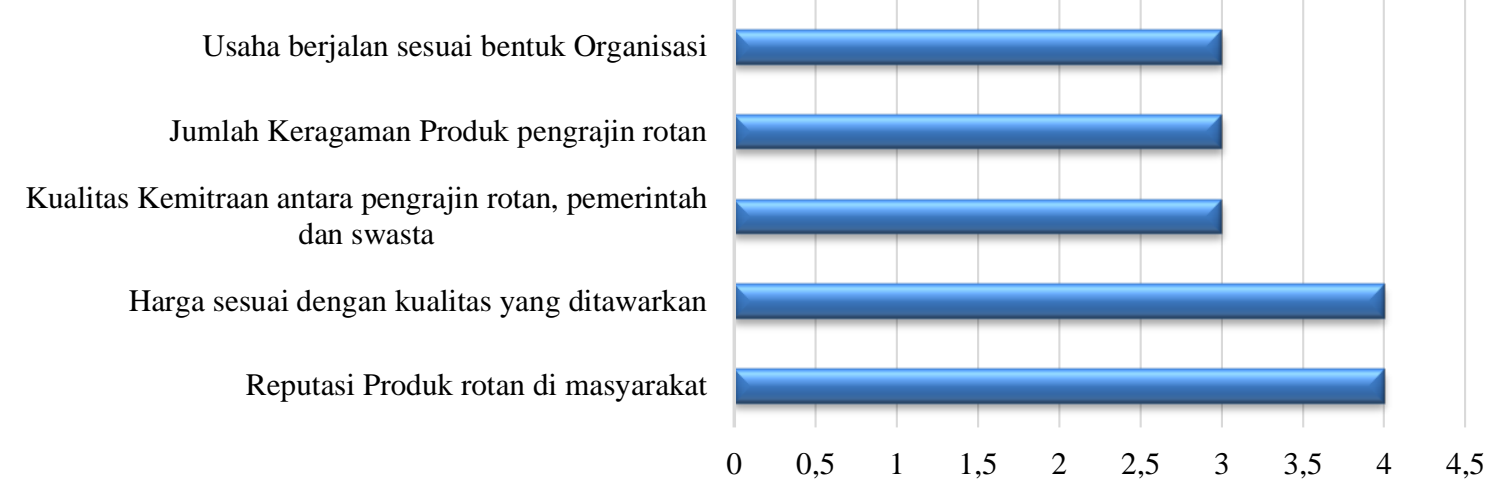

Sumber: (Data Olahan, 2019)

\section{Gambar 4. Rekapitulasi Analisis Faktor Kekuatan}

Berdasarkan gambar 4 maka faktor kekuatan dengan indikator Harga, Reputasi mendapatkan nilai 4 (Empat) sedangkan indikator yang lain seperti kemudahan menyediakan mesin, struktur organisasi, keragaman produk, kemitraan mendapatkan nilai di rata-rata 3 (tiga).

\section{Kelemahan}

Pengrajin rotan Kota Pekanbaru selama ini masih rendah di dalam berinovasi dimana hampir seluruh produk yang ditawarkan dari seluruh pengrajin hampir sama tidak ada perbedaan mencolok. Pengrajin rotan di Pekanbaru juga telah melaksanakan kegiatan promosi yang berbentuk promosi penjualan (sales promotion) dengan cara menunggu di depan toko perabot rotan. Selain itu pelaksanaan promosi penjualan melalui pameran. Berdasarkan data yang didapat, terdapat 6 pengusaha atau 26,08\% yang menggunakan modal Rp. 15.000.000,Rp. 20.000.000,- kemudian ada 4 orang pengusaha atau 17,40\% yang menggunakan modal antara Rp. 9.000.000,- - Rp. 14.000.000,- dan sebanyak 13 orang pengusaha atau 56,52\% yang menggunakan modal antara Rp. 3.000.000,-- Rp. 8.000.000,-. Jadi dapat disimpulkan bahwa modal awal para pengrajin rotan tergolong rendah yaitu antara Rp. 3.000.000,- - Rp 8.000.000,-. Mayoritas pengrajin rotan hanya berpendidikan Sekolah lanjutan tingkat pertama (SLTP) yaitu sebanyak 55 orang atau 56,70\%. 26 orang tenaga kerja atau 26,80\% berpendidikan Sekolah Dasar (SD) selebihnya sebanyak 16 orang yang rata-rata adalah pengusaha industri kerajinan rotan sendiri atau $16,50 \%$ berpendidikan Sekolah Lanjutan Tingkat Atas (SLTA).

Sumber Daya Manusia atau Pengrajin rotan adalah orang yang bekerja di usaha kerajinan rotan yang memiliki kemampuan dan keahlian seni tinggi dalam mengolah rotan menjadi kerajinan-kerajinan rotan. Namun sekarang pengrajin-pengrajin biasa yang pernah bekerja di Usaha Mikro Kerajinan Rotan mendirikan sendiri usaha kerajinan rotan dengan modal mereka sendiri. Sehingga pengrajin yang professional sangat sulit didapatkan, karena mereka lebih memilih untuk mendirikan usaha kerajinan rotan sendiri dan menjadi bos di usaha mereka. Lokasi Kerajinan rotan ini yang dari dulu sampai sekarang menjadi 
permasalahan, karena tempat Usaha Mikro Kerajinan Rotan ini berada di tepi jalan Yos Sudarso Rumbai, sehingga biasanya konsumen parkir di badan jalan, sehingga sangat berbahaya dan dapat mengganggu jalannya lalu lintas.

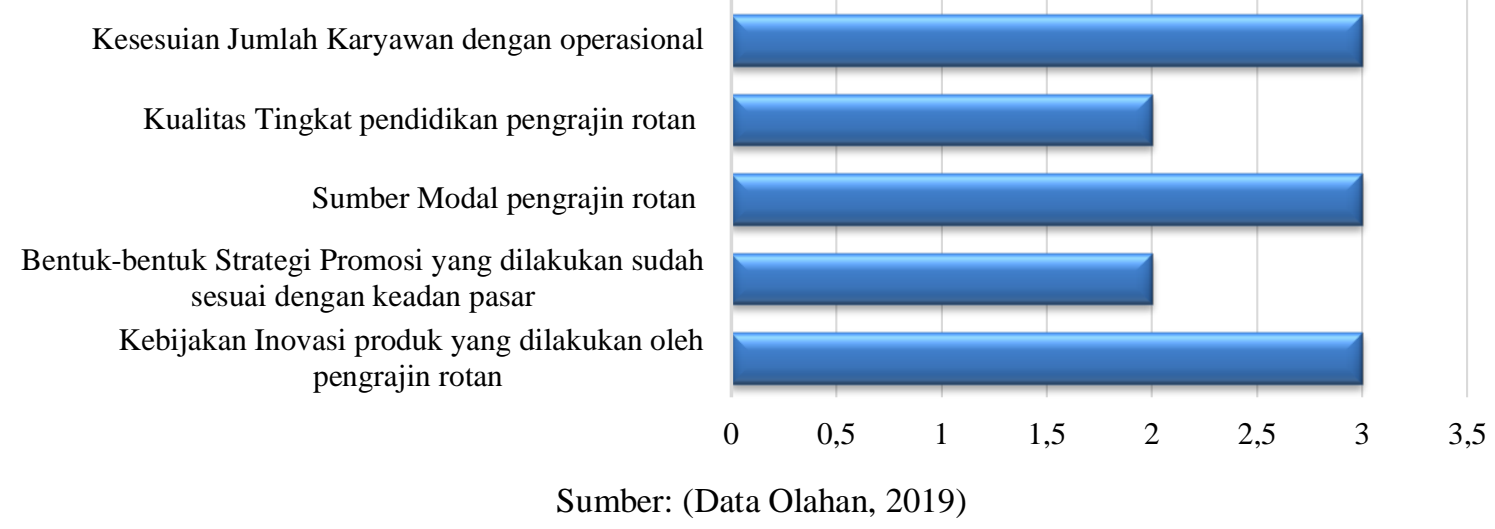

Gambar 5. Rekapitulasi Analisis Faktor Kelemahan

Berdasarkan gambar 5 maka faktor kelemahan dengan indikator kesesuaian jumlah karyawan, sumber modal dan inovasi mendapatkan nilai rata-rata 3 (tiga), sedangkan indikator kualitas dan strategi promosi mendapatkan rata-rata 2 (dua) yang cukup rendah.

\section{KESIMPULAN DAN SARAN}

Berdasarkan hasil dan pembahasan diatas disimpulkan faktor strategis yang membuat pengrajin rotan dapat bertahan hingga saat ini adalah Kesesuaian harga dan Reputasi dengan nilai rata-rata 4 (empat), Sedangkan indikator-indikator yang masih lembah yaitu bentuk promosi, kualitas pendidikan, Perkembangan Inflasi, Program CSR dan Program pembinaan UKM dengan nilai rata-rata 2 (dua). Oleh karena itu peneliti menyarankan agar Pengrajin Rotan Kota Pekanbaru untuk mempertahankan strategi harga yang telah ditetapkan, menjaga reputasi produk-produk rotan Pekanbaru masih memiliki kualitas yang baik. Sedangkan, untuk indikator-indikator yang masih lembah agar seluruh lini seperti Swasta, Pemerintah dan pengrajin membuat workshop bersama guna menyusun strategi-strategi guna menaikkan nilai dari indicator yang masih lembah salah satunya adalah pendidikan dan modal.

\section{DAFTAR PUSTAKA}

Abidin, M. Z. (2015). Kebijakan fiskal dan peningkatan peran ekonomi UMKM. Retrieved from Ministry of Trade: Http://Www. Kemenkeu. Go. Id/En/Node/47721.

Bertuahpos. (2017a). Sepi peminat, pengrajin rotan di Pekanbaru masih tetap eksis.

Bertuahpos. (2017b). Tantangan pengrajin rotan Pekanbaru, tengah kebangkitan ekonomi.

David, F. R. (2010). Strategic management, (12 edition). New Jersey: Pearson Education.

Disperinriau. (2017). Jumlah UKM pengrajin rotan Pekanbaru.

Elbanna, S. (2010). Strategic planning in the United Arab Emirates. International Journal of Commerce and Management, 20(1), 26-40. https://doi.org/10.1108/10569211011025934 
Fred R. D. (2011). . Manajemen strategis konsep, (Edisi 12). Jakarta: Salemba empat.

Hemmatfar, M., \& Ph, D. (2010). Competitive advantages and strategic information systems. International Journal of Business and Management, 5(7), 158-170. https://doi.org/www.ccsenet.org/ijbm

Keller, P. K. and K. L. (2012). Marketing management (14e Global). England: Pearson education.

Nella Marni. (2016). Omzet pengrajin rotan di Rumbai capai rp15 juta per bulan.

Nofrizal, N. (2018). Model dan strategi pengembangan makanan lokal daerah (studi kasus pada Kabupaten Meranti \& Kabupaten Bengkalis Provinsi Riau). Benefit: Jurnal Manajemen dan Bisnis, 3(1), 64-73.

Porter, M. E. (1995). Strategi bersaing, teknik menganalisis industri dan pesaing. Jakarta: Erlangga.

Soviyanti, E., Khairani, Z., Ciptono, W. S., \& Hanafi, M. M. (2019). Finding most effective strategy for SMEs food souvenir in Indonesia. Academy of Strategic Management Journal.

Stonehouse, G., \& Snowdon, B. (2007). Competitive advantage revisited: Michael Porter on strategy and competitiveness. Journal of Management Inquiry, 16(3), 256-273. https://doi.org/10.1177/1056492607306333

Sudaryanto, R., \& Wijayanti, R. R. (2013). Strategi pemberdayaan UMKM menghadapi pasar bebas Asean. Pusat Kebijakan Ekonomi Makro. Badan Kebijakan Fiskal. Kementerian Keuangan, Jakarta.

Thomas L Wheelen, J David Hunger, Alan N Hoffman, C. E. B. (2015). Strategic management and business policy: Globalization, innovation and sustainability. Global Edition. Pearson Higher Ed. 